Waste and Resource Management Volume 170 Issue WR2

Briefing: Resource scarcity and resource security - a suppressed civil engineering challenge

Rogers, Hunt, Leach, Purnell and Roelich

ice proceedings

\title{
Briefing: Resource scarcity and resource security - a suppressed civil engineering challenge
}

Chris D. F. Rogers Eur Ing, BSC, PhD, CEng, MICE, MCHIT Professor, Department of Civil Engineering, University of Birmingham, Birmingham, UK (corresponding author: c.d.f.rogers@bham.ac.uk)

Dexter V. L. Hunt MEng, PhD, CEng, MICE, FHEA

Lecturer, Department of Civil Engineering, University of Birmingham, Birmingham, UK

Joanne M. Leach BSc, MSc

Research Fellow, Department of Civil Engineering, University of

Birmingham, Birmingham, UK
Phil Purnell BEng, PhD

Professor, School of Civil Engineering, University of Leeds, Leeds, UK

Katy E. Roelich BSC, MSC, PhD, CEng, MCIWEM, FHEA

Senior Research Fellow, School of Civil Engineering, University of Leeds, Leeds, UK

While natural and manufactured resources provide the raw materials with which civil engineers work, the term 'resources' should always be considered in its wider interpretation and then in the context that resources are in many cases limited. That they should be used wisely (resource efficiency) is beyond contention - we do this as a matter of course - yet considerations of where and how resources are obtained and refined for use are far less likely to feature in a civil engineer's psyche. Similarly, considerations of resource availability for others now, and importantly in the future, and the vulnerability of these resources to future supply disruption (e.g. for geopolitical reasons) are likely not to be in the forefront of our thinking when conducting our routine business. The ICE Research, Development \& Innovation towards Engineering Excellence panel has chosen this topic as one of pressing importance across all the sectors that comprise civil engineering. Accordingly, the panel is promoting this topic for Research \& Development Enabling Fund (R\&DEF) proposals. This briefing note describes the prior work of the panel in exploring the extent of this issue, along with insights from current research, to raise awareness, encourage $R \& D E F$ proposals and prime debates on this topic.

Natural and manufactured resources provide the raw materials with which civil engineers work (conceive, plan, design) and from which civil engineering artefacts are made (construction), used (operation, maintenance) and decommissioned (reuse, recycle, recovery). The term 'resources', however, has far wider interpretations, embracing people, skillsets, finance and suchlike, while the metabolism of urban and rural centres of population, no matter what the scale, rely wholly on the flows of resources - water, energy and food being core requirements. All are important influences on the civil engineers' role and all need consideration in terms of current and future scarcity and security, yet it is the challenge presented by the former, broadly physical, resources that should perhaps be of most immediate concern. This is because it affects every aspect of the discipline, is of fundamental importance, embodies numerous dependencies and interdependencies that cut across the 'engineering silos' of expertise, and is in danger of being neglected. A graphic example is provided by the fact that construction, indeed reinforced concrete production alone, accounts for more than half of all global resource extraction (Purnell, 2013).

The issues surrounding resource scarcity and resource security, while not new, are not well understood in terms of risks and opportunities by practicing civil engineers. Moreover, the needs of future generations of civil societies and civil engineers are not uniformly well considered when making decisions on what should be consumed today to meet current and near future needs. In one sense this is hardly surprising, since a civil engineer will rely heavily on past experience to inform the surety of designs and constructions working with tried and tested natural and manufactured resources, albeit in innovative applications, engenders confidence and can lead to efficiencies (e.g. the need not to overdesign to account for uncertainty). Nevertheless a civil engineer's role is, rightly, constrained by seemingly ever more ethical and practical considerations, ranging from carbon dioxide emissions reduction, sustainability and resilience (in the face of climate change, and more widely) to demographic changes in the societies that civil engineers support with their activities. A complex set of issues face today's civil engineering decision makers, and these naturally extend to raw materials.

The UK government addressed the topic in a report (Defra, 2012) that provides a useful introduction, yet one that is very much focused on a UK business perspective and necessary 
actions in relation to the supply of metals and minerals. The risks relate to factors such as the following.

- Increasing competition for resources, price volatility and potential interruptions in supply, all influenced by a combination of growing worldwide demand, which is fuelled by a growing global population, global movements towards 'western lifestyles' and implementation of low-carbon agendas by way of new infrastructure technology. The demand for mineral resources from China is one of several topical examples.

- Resources not being available at the correct time and place within a country - for example, aggregate shortages in southeast England, and mismatch between construction and demolition waste arisings with potential for recycling and demand for recycled aggregate.

- Concentration of supply of certain natural resources in a small number of countries.

- In some cases, trade restrictions or political barriers to the sourcing of materials.

- Lack of currently viable alternatives in key applications. While this is usually viewed in terms of material substitutions, technology and component substitutions are equally important in this respect.

- Time lags in the supply response to increased demand.

Among this somewhat volatile landscape lie associated concerns including prices for resources not reflecting the full environmental cost of extraction, a lack of readily available information about resource risks and behavioural, cultural, regulatory and legislative barriers that impede action to improve resource efficiency (Defra, 2012). While the report focuses on the UK economy, citing the UK's prosperity and national security as key drivers for action, it acknowledges associated potential environmental impacts - for example, where easily accessible resources have been exploited, opening up new sources of supply often involves more energy-intensive mining and refining, with higher greenhouse gas emissions and increased demands on water supplies and other natural systems. As should always be the case, civil engineers necessarily balance economic, social and environmental considerations when going about their activities, but there is usually an underlying economic imperative to what is done (cf. the 'cost, quality, time' mantra) and to public or private governance of the activity (i.e. profit, economic growth, cost savings etc.).

This debate provides the wider context of the starting point for much of civil engineers' activities, and poses fundamental questions on how they should go about their business. For example, is it more a question of 'resource security', where a short-term disruption in supply might impede their activities - with known and easily-exploitable resources being cited to support such arguments - or genuine 'resource scarcity' with the potential for resource depletion? Is it the responsibility of current civil engineers to safeguard resources that will be consumed in an uncertain manner in an uncertain future, or should they use those resources at their disposal safe in the knowledge, or hope, that future civil engineers will innovate with what they have according to the situation that presents itself then? After all, the root of the term 'engineer' is 'ingenuity'. Taking a responsible attitude to these matters can, of course, produce more immediate benefits. For example, any action that can reduce demand for critical materials will reduce exposure to risk, and this might translate into improvements in design, or the optimisation of reuse, recycling, recovering, or sustainably substituting for material, components and/or technology already in circulation. A case in point would be where there is a trade-off in installing more 'efficient' technologies at the expense of system robustness - incorporating technodiversity within systems to avoid lock-in to technologies potentially at risk of disruption (e.g. due to exposure to critical materials) might be considered less efficient but more resilient; should civil engineers be instrumental in delivering short-term savings or investment in longer-term resilience?

Tied into the argument surrounding resources is the issue of waste, and how civil engineers deal with it. The National Needs Assessment for UK infrastructure (ICE, 2016) reports on the UK's progress towards recycling and movement away from landfilling, yet states that 'opportunities for recovery of valuable resources from waste are still under-exploited'. For this to be truly effective there is a need to shift mindsets away from the traditional paradigm of extract-refine-use-dispose: the 'linear view of resource management'. So what does this mean for civil engineers' use of materials (concrete, steel, timber), and manufactured components (beams, columns), both now and when they have served their first purpose?

However, there is a more searching underlying question: which materials should they be targeting, and where should they be looking to change their designs to deliver best overall value to the economy, society and the environment while ensuring that future generations are not compromised? Such questions have been picked up in the relatively recent advancement of ideas of a 'circular economy'. For example: 'A circular economy is one that is restorative and regenerative by design, and which aims to keep products, components and materials at their highest utility and value at all times, distinguishing between technical and biological cycles' (EMF, 2016), and 'A circular economy is an alternative to a traditional linear economy (make, use, dispose) in which we keep resources in use for as long as possible, extract the maximum value from them whilst in use, then recover and regenerate products and materials at the end of each service life' (WRAP, 2016). Operationalising these 
ideas and ideals is far from straightforward, yet they provide a valuable base on which to develop thinking and action, and evidence on which to base decisions is emerging.

For example, there is a body of research that is starting to underpin the decisions that civil engineers need to make, both from materials (Purnell and Roelich, 2014; Sure-Infrastructure, 2017) and urban metabolism (Liveable Cities, 2017) perspectives, while the value that civil engineers deliver, for example, by way of the physical infrastructures that they create, is starting to inform an alternative set of business models to support their financing (iBUILD, 2017). Moreover, techniques have been developed to understand the likely future value and consequences of the interventions that civil engineers make in the constructed landscape (Lombardi et al., 2012; Rogers et al., 2012), and this is only to mention those research activities with which the authors are directly concerned; far more is being done UK-wide. However, equally, if not more, important is the variety of perspectives of, and issues faced by, practitioners who are bringing about changes in constructed environments and, de facto, creating the legacies for tomorrow's societies and those that are required to shape them. Marrying the two, and defining the way forward, has been identified as a primary concern and has been selected as an appropriate cross-cutting theme for the Spring 2017 Call for Proposals for the ICE's Research \& Development Enabling Fund. The findings from this $R \& D$ are required to be presented at a half-day event, as well as to form the subject of papers and/or briefing notes to be published in relevant parts of the ICE Proceedings and other forms dissemination, thus ensuring that they are brought to the attention of the ICE's members. In preparation for this Call for Proposals, a workshop was held with representatives from the ICE's Innovation \& Research Panel, academia, consulting and contracting industries, the Highways Agency, Natural England, WRAP, Defra, International Synergies, EPSRC and the Technology Strategies Board, though more specifically it concerned invited individuals who are central to these debates.

The following is a summary of the questions that need to be addressed and challenges embraced by the profession, as revealed by the workshop discussions.

- From an engineering perspective, what is meant by 'resources' - natural resources, whether material or non-material (e.g. land, water, energy); manufactured resources?

- What is the interplay between resource scarcity, criticality, security and efficiency?

- What roles, responsibilities and capabilities do (or should) engineers have to improve resource efficiency, enhance resource security and reduce resource scarcity? How can civil engineers be empowered to be ambassadors for responsible resource use (e.g. by way of education, tools, regulations, codes and standards)?

- How should engineers inform and influence clients on resource issues, acknowledging that some are interested in construct-and-sell (i.e. minimising 'first costs'), while others have an interest in minimising operational, maintenance and decommissioning costs?

- Who should be responsible for resource stewardship, and how might an operational system be devised?

- How is it possible to reach a proper symbiosis between the natural and built environments - that is, both supporting and exploiting ecosystem services and natural resources?

- To what extent do regulatory and decision-making environments militate against responsible resource use? What might more supportive policy look like?

- How do (and should) codes and standards mandate or encourage responsible resource use?

- How should the local context influence the thinking and practice of resources consumption (local abundance versus local scarcity)? How do such considerations then relate to the national and global perspectives?

- Given claims that $50 \%$ of the UK's national wealth lies in its infrastructure, more than $50 \%$ of construction is engaged in repair and maintenance of the nation's infrastructure and rising UK populations mean that more infrastructure will be required, is increasing the functional life of infrastructure an effective means of tackling resource issues? Do current 'business models' need to change to reflect this?

- UK designs are typically conservative, so when is overdesign helpful in providing additional functional life (hence reducing long-term resource use) and when does it represent an unnecessary overuse of resources? In what way would design and construction processes need to become more sophisticated, or perhaps nuanced, to take account of these resource issues? How might lean construction and adaptability be used to maximise responsible resource use? How can the temporal and spatial mismatch between resource use now and resource implications in the future be addressed, and the resource demands evaluated?

- Since engineering designs 'lock-in' user behaviours (hence resource consumption), how might designs for responsible resource consumption during operation be encouraged?

- What are the resource implications of progressively increasing density of city living, this being a commonly-advocated response to growing city populations?

- If current undervaluing of resources contributes to their overuse and dispersion, is there a need to change the units used to value resources (e.g. to reflect embodied carbon, water etc.), the parts of the life cycle upon which value is placed (e.g. whole life costing versus capital costing), and/or current business models to more accurately reflect holistic valuing of resources? 
- Resources have a hierarchy of potential (potable water versus toilet flushing, virgin aggregates versus recycled aggregates), therefore can industrial symbiosis and/or circular economy principles be applied to enable more responsible resource use (greywater recycling, sub-base/capping/fill)? How can what is currently considered 'waste' become more routinely and universally considered to be a resource (cf. the urban mines concept), and how can the production of low-value co-products be prevented (i.e. such that there is no such thing as waste)?

- Should there be a priority order for the use for resources, driven by current and future need rather than the market?

- How is it possible to accelerate changes to procurement practices, supply chains, design processes and business models, which have been slow to respond to the increasing awareness of the issues surrounding the scarcity and overuse of resources?

- What would 'Fairtrade' look like for civil engineering resource procurement? Can an efficiency rating be created for civil engineering resource use?

- How might alignment be created between who pays and who benefits in relation to resource use?

- How can responsible resource use effectively be used as a driver of innovation and competitive advantage?

- Are there lessons to be learned from or provided to other sectors? Is there good practice to be drawn from other countries?

The UK has an opportunity to set the standard and provide a world lead in this area, and export the thinking to developing countries whose resource use is yet to peak - how is this best achieved?

The above should set the agenda for civil engineers' current thinking, while a distillation of research, development, innovation and case studies of good practice that currently permeates the profession would provide policy-makers and practitioners with the evidence base for making the radical changes needed to move towards a more sustainable and resilient future. It would therefore be helpful if such evidence could emerge alongside the findings of the R\&D Enabling Fund research.

That the issue of resources and waste is topical generally is beyond doubt (e.g. see GO Science, 2017), yet it is important not only to raise awareness among the ICE's members, but to fundamentally change practice, hence the new initiative. Contributions to this debate are consequently most welcome.

\section{REFERENCES}

Defra (Department for Environment, Food and Rural Affairs) (2012)

Resource Security Action Plan - Making the Most of Valuable Materials. Defra and BIS, London, UK. See http://www.gov. uk/government/publications/resource-security-action-plan-makingthe-most-of-valuable-materials (accessed 12/04/2017).

EMF (Ellen MacArthur Foundation) (2016) http://www. ellenmacarthurfoundation.org/circular-economy (accessed 09/11/2016).

GO Science (2017) From Waste to Resource Productivity. Chief Scientific Advisor's Annual Report. Government Office for Science, London, UK.

iBUILD (2017) http://research.ncl.ac.uk/ibuild/ (accessed 28/04/2017).

ICE (Institution of Civil Engineers) (2016) National Needs Assessment - A Vision for UK Infrastructure. Institution of Civil Engineers, London, UK.

Liveable Cities (2017) http://www.liveablecities.org.uk (accessed 28/04/2017).

Lombardi DR, Leach JM, Rogers CDF et al. (2012) Designing Resilient Cities: A Guide to Good Practice: (EP103). IHS BRE Press, Bracknell, UK.

Purnell P (2013) The carbon footprint of reinforced concrete. Advances in Cement Research 25(6): 362-368, http://dx.doi.org/10.1680/ adcr.13.00013.

Purnell P and Roelich KE (2014) What will Future Cities be Made of? Thinkpiece, Foresight Future of Cities Project. University of Leeds, Leeds, UK. See http://www.gov.uk/government/publications/futureof-cities-what-will-cities-of-the-future-be-made-of (accessed 12/04/2017).

Rogers CDF, Lombardi DR, Cooper RFD and Leach JM (2012) The urban futures methodology applied to urban regeneration. Proceedings of the Institution of Civil Engineers - Engineering Sustainability 165(1): 5-20, http://dx.doi.org/10.1680/ensu.2012.165.1.5.

Sure-Infrastructure (2017) http://sure-infrastructure.leeds.ac.uk/ui/ (accessed 28/04/2017).

WRAP (Waste and Resources Action Programme) (2016) http://www.wrap. org.uk/content/wrap-and-circular-economy (accessed 09/11/2016).

\section{How can you contribute?}

To discuss this briefing, please email up to 500 words to the editor at journals@ice.org.uk. Your contribution will be forwarded to the author(s) for a reply and, if considered appropriate by the editorial board, it will be published as discussion in a future issue of the journal.

Proceedings journals rely entirely on contributions from the civil engineering profession (and allied disciplines).

Information about how to submit your paper online is available at www.icevirtuallibrary.com/page/authors, where you will also find detailed author guidelines. 